\title{
Heat and mass transfer in the mushroom- shaped head of mantle plume
}

\author{
Anatoly Kirdyashkin ${ }^{1}$, Alexey Kirdyashkin ${ }^{1,2, *}$, and Vladimir Gurov ${ }^{1}$ \\ ${ }^{1}$ V.S. Sobolev Institute of Geology and Mineralogy, Siberian Branch of the Russian Academy of \\ Sciences, pr. Akademika Koptyuga 3, Novosibirsk, 630090, Russia \\ ${ }^{2}$ Novosibirsk State University, ul. Pirogova 2, Novosibirsk, 630090, Russia
}

\begin{abstract}
The results of experimental and theoretical modeling of freeconvection flows in the melt of the plume conduit and in the mushroomshaped head are presented. It was shown that the plumes with the mushroom-shaped heads can be responsible for the batholith formation. The main parameters of such plumes are estimated.
\end{abstract}

\section{Introduction}

The mantle plumes manifest themselves as localized conduits of heat transfer from the core-mantle boundary to the Earth's surface and represent magma melt conduits surrounded by the mantle [1]. In the model [1], a thermochemical mantle plume forms at the coremantle boundary at the locations where local chemical doping has decreased the melting point to the value of $T_{\mathrm{mc}}<T_{1}$, where $T_{1}$ is the temperature of the core-mantle boundary. In this case, the melting of the mantle matter proceeds and the plume forms. The outer core is a heat source. The chemical dope is formed by the reactions of lower mantle minerals with hydrogen and/or methane brought to the lower mantle from the outer core [1].

\section{Structure and main parameters of plumes with mushroom- shaped heads}

Let us consider a structure of a thermochemical plume. According to the laboratory modeling, in its vertical section, the plume conduit is a system of convection cells (Fig. 1A). In narrowed zones at the boundaries of cells, the ascending convection flow transits to the opposite side of the conduit. The boundary layer of the descending convection flow is located along the sidewall of the conduit. The conduit boundary changes with time. Melting occurs along the ascending flow domain, whereas crystallization (at the conduit boundary and in the zones of conduit narrowing) along the descending one. The conduit surface is a "traveling wave;" nonstationary conductive heat transfer takes place between the conduit boundary and the surrounding mantle. The diameter $d=2 R$ ( $R$ is the conduit radius) of the plume conduit is comparable to the diameter of the plume base. The diameter of narrowing is $d_{\mathrm{n}}=2 R_{\mathrm{n}}=0.5 d$ ( $R_{\mathrm{n}}$ is the radius of narrowed zone). According to [2], a mantle plume

${ }^{*}$ Corresponding author: aak@,igm.nsc.ru 
originates and ascends from the core-mantle boundary as a thermochemical plume to the level $x_{\mathrm{tc}}=148-185 \mathrm{~km}$. For the formation and the ascent of the thermochemical plume to the level $x=x_{\mathrm{tc}}$ the diffusion process is a controlling factor. For $x>x_{\mathrm{tc}}$ thermal processes represent the controlling factor rather than diffusion processes. The plume lifetime is $10-$ $70 \mathrm{Ma}$. We adopt, as the thermal power scale, the thermal power transferred from the plume conduit to the surrounding mantle under steady-state thermal conduction conditions. This thermal power is defined by the relation: $N 1=0.5 \pi \lambda_{\mathrm{sm}} \Delta T H$, where $\lambda_{\mathrm{sm}}$ is the thermal

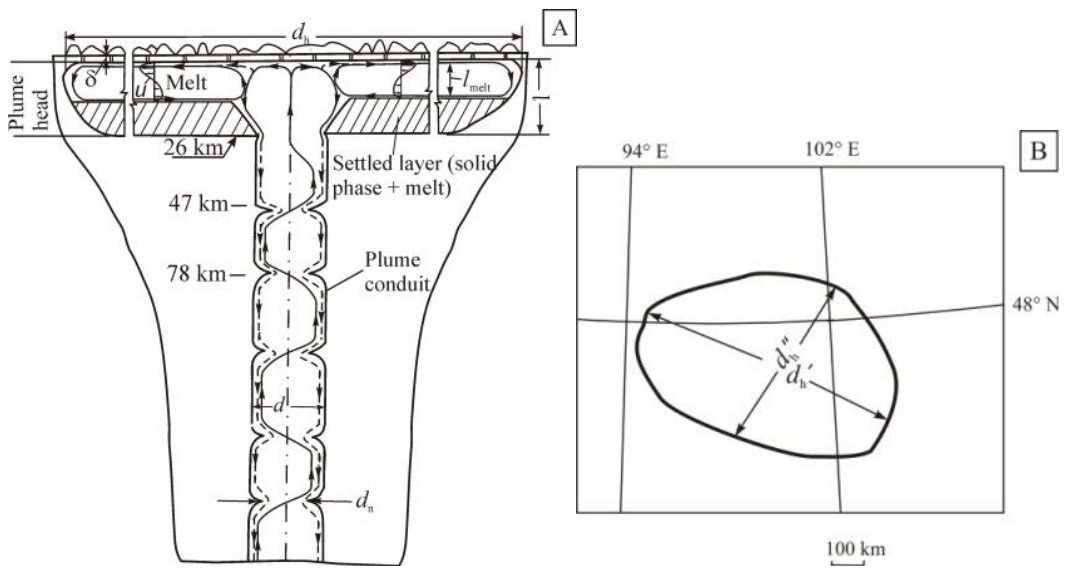

Fig. 1. Plume with the mushroom-shaped head. (A) Schematic of the thermochemical plume and freeconvection flows in the plume conduit and the plume head on the data of our laboratory modeling. The scale is with reference to the diameter of the Khangai plume conduit $(d=32.5 \mathrm{~km})$. (B) Contour of projection of the Khangai plume head on the Earth's surface constructed using data [3].

conductivity of the surrounding mantle averaged over the height of the plume conduit, $\Delta T=T_{\mathrm{m}}-T_{0}$ is the temperature difference averaged over the height of the plume conduit, $T_{\mathrm{m}}$ is the temperature of the plume conduit boundary, $T_{0}$ is the temperature of the surrounding mantle, $H$ is the height of the melted plume conduit. Let us consider the relative thermal power of the plume $\mathrm{Ka}=N / N_{1}$, where $N$ is the thermal power of the plume source, i.e. the thermal power transferred from the plume base to the conduit. Thus, the Ka number refers to the ratio of the thermal power at the plume base to that released to the mantle at steady-state thermal conduction.

Further, we obtain relations for the thermal power and plume diameters. The thermal power transferred from the plume base to the conduit is $N=\Delta G C / \beta$, where $\Delta G$ is the mass flow rate of magmatic melt erupted on the surface which is determined using geological data, $\beta$ is the thermal expansion coefficient, and $C$ is the mantle specific heat. We obtain the diameter of the plume conduit $d$ using the equality [2]: $d=\left[N(a v)^{1 / 3} / 0.045 \pi \lambda \Delta T_{\mathrm{s}}^{4 / 3}(\beta g)^{1 / 3}\right]^{1 / 2}$, where $a$ is the thermal diffusivity of melt in the plume conduit, $v$ is the kinematic viscosity of the melt, $\lambda$ is the thermal conductivity of the melt, $\Delta T_{\mathrm{s}}=\left(T_{1}-T_{\mathrm{mc}}\right) / 1.57$ is the temperature difference across the boundary layer at the plume base, and $g$ is the gravitational acceleration.

In the case of plumes having the relative thermal power $1.9<\mathrm{Ka}<10$, after the melt erupts on the surface through the eruption conduit, the surrounding crustal block melts and a mushroom-shaped plume head of thickness $l$ forms (Fig. 1A). Plumes with mushroomshaped heads can be responsible for the formation of large intrusive bodies (batholiths). In particular, these plumes can be responsible for the formation of the largest granitic batholiths such as the Khangai (Fig. 1B) and Khentei ones. The Khangai and Khentei batholiths are located respectively in Central and North-Eastern Mongolia. 
After melt erupted to the surface, the thermal power transferred to the plume roof is $\Delta N=N-N_{\text {liml }}$, where $N=\mathrm{KaN}_{1}$ is the thermal power transferred from the base of the plume to its conduit, $N_{\lim 1}=\mathrm{Ka}_{\lim 1} N_{1}$ is the limiting thermal power transferred from the plume conduit to the surrounding mantle by unsteady-state thermal conduction. The value of $\mathrm{Ka}_{\lim 1}$ is set equal to 1.15 in accordance with the results of laboratory modeling [2]. The limiting thermal power is $N_{\lim 1}=1.6 \cdot 10^{10} \mathrm{~W}$. The thermal power transferred from the plume roof to the atmosphere through the block of thickness $\delta$ above the plume roof is much less than the thermal power $\Delta N$. Therefore melting occurs along the base of the block located in the crust above the plume roof, resulting in the formation of a mushroom-shaped head of the plume, i.e., a root batholith (Fig. 1A).

Consider the case when the mushroom-shaped head of the plume reaches its maximum diameter $d_{\mathrm{h}, \max }$ at the instant $t=t_{\text {melt }}$. This occurs when thermal power $\Delta N=N-N_{\lim 1}$ becomes equal to the thermal power transferred to the atmosphere through the block of thickness $\delta$. The heat flux through the block is $q_{\mathrm{cb}}=\lambda_{\delta}\left(\Delta T_{\delta} / \delta\right)$, where $\lambda_{\delta}=3.5 \mathrm{~W} /\left(\mathrm{m} \cdot{ }^{\circ} \mathrm{C}\right)$ is the thermal conductivity of the block, $\Delta T_{\delta}=T_{\mathrm{r}}-T_{\mathrm{sf}}=1200{ }^{\circ} \mathrm{C}, T_{\mathrm{r}}$ is the temperature of the plume roof, and $T_{\mathrm{sf}}$ is the temperature of the ground surface. The amount of heat transferred through the block corresponds to the thermal power $\Delta N=\left(\mathrm{Ka}-\mathrm{Ka}_{\lim 1}\right) N_{1}$. The surface area of the mushroom-shaped plume head $S_{\mathrm{h}}=\pi d_{\mathrm{h}}^{2} / 4=\Delta N / q_{\mathrm{cb}}\left(d_{\mathrm{h}}\right.$ is the plume head diameter). Then, using the equalities for $q_{\mathrm{cb}}$ and $\Delta N$, we obtain $S_{\mathrm{h}}=N_{1} \delta\left(\mathrm{Ka}-\mathrm{Ka}_{\lim 1}\right) / \lambda_{\delta} \Delta T_{\delta}$, $d_{\mathrm{h}}=\left[4 N_{1} \delta\left(\mathrm{Ka}-\mathrm{Ka}_{\lim 1}\right) / \pi \lambda_{\delta} \Delta T_{\delta}\right]^{1 / 2}$.

The main parameters of plumes with mushroom-shaped heads have been estimated. Melt pressure under the plume roof exceeds the lithostatic pressure for the value $\Delta P$ [1]. In view of the necking of the plume conduit, the superlithostatic pressure is $\Delta P=\rho_{0} \beta g\left(H-x_{\mathrm{cr}}\right)\left(T_{\mathrm{m}}-T_{0}\right)\left(R_{\mathrm{n}} / R\right)^{2}$, where $\rho_{0}$ is the density of the surrounding mantle, $x_{\mathrm{cr}}$ is the height of the eruption conduit. The thickness of the crustal block above the mushroomshaped plume head $\delta$ is defined by relation: $\delta=\left(2 F / c \rho_{\mathrm{cb}} g\right)^{2 / 5}\left[\lambda_{\delta} \Delta T_{\delta} / 4 \pi N_{1}\left(\mathrm{Ka}-\mathrm{Ka}_{\lim 1}\right)\right]^{1 / 5}$, where $F$ is the total pressure force on the top of the mushroom-shaped plume head, $c=0.28$ for a wide range of minerals [1], $\rho_{\mathrm{cb}}$ is the average density of the crustal block. For Khangai plume we obtain $\delta=5.1 \mathrm{~km}$, for Khentei plume $\delta=5.9 \mathrm{~km}$. For a constant thermal power of the plume $\left(N=\mathrm{Ka} N_{1}=\right.$ const $)$, the volume $\Delta V$ of magmatic melt intruded into the block per unit of time under the effect of the superlithostatic pressure $\Delta P$ is determined using the relation $\Delta V=\beta N / \rho C$, where $\rho$ is the density of melt. Probably, a large mass of magma intrudes into more ancient rocks in the weakest places. It pushes those rocks apart when moving upwards. Thus, magma intrudes into fault zones in the crustal block above the plume head under the effect of superlithostatic pressure $\Delta P$. In these zones, localized surface manifestations of batholiths are most probable (Fig. 1A). With the closure of a fault, another fault forms in the block, and magma intrudes into this new fault, etc.

For Khangai plume $d=32.5 \mathrm{~km}, d_{\mathrm{h}}=349 \mathrm{~km}$, for Khentei plume $d=29 \mathrm{~km}$, $d_{\mathrm{h}}=329 \mathrm{~km}$. The distribution of the Khangai (Fig. 1B) and Khentei batholiths is asymmetrical. The maximum size of these batholiths $d_{\mathrm{h}}{ }^{\prime}$ is observed in longitudinal direction, while the minimum size $d_{\mathrm{h}}{ }^{\prime \prime}$ is observed in latitudinal direction [3]. For example, for the Khangai batholith $d_{\mathrm{h}}{ }^{\prime} \approx 740 \mathrm{~km}, d_{\mathrm{h}}{ }^{\prime \prime} \approx 317 \mathrm{~km}$ (Fig. 1B), and $d_{\mathrm{h}}{ }^{\prime} / d_{\mathrm{h}}{ }^{\prime \prime} \approx 2$. For the Khentei batholith $d_{\mathrm{h}}{ }^{\prime} \approx 700 \mathrm{~km}, d_{\mathrm{h}}{ }^{\prime \prime} \approx 224 \mathrm{~km}$, and $d_{\mathrm{h}}{ }^{\prime} / d_{\mathrm{h}}{ }^{\prime \prime} \approx 3$. Probably, the elongation of the batholiths in the longitudinal direction is due to the effect of the Coriolis force, which manifests itself at a relatively low kinematic viscosity of melt $v=1-10 \mathrm{~m}^{2} / \mathrm{s}$.

Within the accuracy of evaluation, the thickness of the molten crustal layer (plume head) $l$ is comparable to the plume conduit diameter $d$. The solid phase fraction for the molten layer can be determined knowing the normative composition of melt. The scheme of free-convection flows in the plume conduit and in the plume head is shown on Fig. 1A. The experimental modeling shows that the ascending free-convection flow occurs along the axis 
of the plume conduit. The horizontal flows are due to the horizontal temperature gradient in the layer.

To a first approximation, we consider the plume head as a flat layer of thickness $l$, length $d_{\mathrm{h}}{ }^{\prime}$ and width $d_{\mathrm{h}}{ }^{\prime \prime}$. The plume head consists of two symmetric horizontal layers of length $0.5 d_{\mathrm{h}}$ '. The thermal power transmitted to the axial plane of the layers is equal to $\Delta N$, and consequently, the thermal power transmitted to each layer is equal to $0.5 \Delta N$. Heat is removed from the plume roof having a temperature $T_{\mathrm{r}}=$ const. Experimental and theoretical investigations of free convection flows in the horizontal liquid layer heated from the buttend are presented in [4]. Consider the maximum temperature difference $\Delta T_{\max }=T_{\text {melt }}-T_{\mathrm{r}}$, where $T_{\text {melt }}$ is the temperature of melt in plume conduit. The difference $\Delta T_{\max }$ is defined using the relation: $\Delta T_{\max }=8(Q / \lambda) \mathrm{Ra}_{Q}{ }^{-1 / 3}$, where $Q=\Delta N / 2 d_{\mathrm{h}}{ }^{\prime \prime}$ is the thermal power delivered per meter run, $\mathrm{Ra}_{Q}=\beta g Q l^{3} / a v \lambda$ is the Rayleigh number. The maximum horizontal velocity of free-convection flow is constant along the layer. It is determined using the relation $u_{\max }=0.707(a / l) \operatorname{Ra}_{Q}{ }^{1 / 3}$. The mean flow velocity is $u=0.42 u_{\max }$. For the Khentei plume $N=7.6 \cdot 10^{10} \mathrm{~W}$ and $\Delta N=6 \cdot 10^{10} \mathrm{~W}$. Then $Q=1.3 \cdot 10^{5} \mathrm{~W} / \mathrm{m}$ for $d_{\mathrm{h}}{ }^{\prime \prime}=224 \mathrm{~km}$. For $l=d=2.9 \cdot 10^{4} \mathrm{~m}, \lambda=3.5 \mathrm{~W} /\left(\mathrm{m} \cdot{ }^{\circ} \mathrm{C}\right), v=1-10 \mathrm{~m}^{2} / \mathrm{s}, \beta=10^{-5}{ }^{\circ} \mathrm{C}^{-1}$ and $a=10^{-6} \mathrm{~m}^{2} / \mathrm{s}$ we obtain $\mathrm{Ra}_{Q}=9.2 \cdot 10^{18}-9.2 \cdot 10^{19}$. During the melting of the plume head in the crustal layer the fraction of unmelted crystallites comprises $1 / 3$ from the overall composition of this layer. In that case, the effective kinematic viscosity of melt ranges from 3 to $30 \mathrm{~m}^{2} / \mathrm{s}$. The corresponding Rayleigh numbers are $\mathrm{Ra}_{Q}=3.1 \cdot 10^{18}-3.1 \cdot 10^{19}$. Then, during the melting of the plume head we have $\Delta T_{\max }=0.10-0.21^{\circ} \mathrm{C}, u_{\max }=3.5 \cdot 10^{-5}-7.6 \cdot 10^{-5} \mathrm{~m} / \mathrm{s}$. The mean flow velocity in the upper and lower halves of the layer is $u=1.5 \cdot 10^{-5}-3.2$. $10^{-5} \mathrm{~m} / \mathrm{s}$. As a consequence of the small superadiabatic temperature differences in the melt of the plume head $\Delta T_{\max }$, the melt temperature $T_{\text {melt }}$ appears to be approximately equal to the melting temperature of the plume head material $T_{\mathrm{m}}$. At constant quantity of heat transferred to the plume head ( $\Delta N=$ const) favorable conditions for the settling of solid phase exist in the plume head within the time of batholith formation $\left(t_{\mathrm{b}}=15-35 \mathrm{Ma}\right)$. The time $t_{\text {melt }}=4.8 \mathrm{Ma}$. During the process of melting of the plume head the settling of suspended solids (refractory minerals) also proceeds. The settled particles make up the settled layer of the plume head. The residual melt forms the upper layer of thickness $l_{\text {melt }}$ (Fig. 1A).

\section{Summary}

The plume conduit has the cellular structure. There are narrowed zones at the convection cell boundaries. For the relative thermal power $1.9<\mathrm{Ka}<10$ the flattened upper cell is mushroom-shaped. The main parameters of the plume with the mushroom-shaped head have been evaluated. These plumes can be responsible for the batholith formation.

The work was supported by state assignment project No. 0330-2016-0016.

\section{References}

1. N.L. Dobretsov, A.A. Kirdyashkin, A.G. Kirdyashkin, V.A. Vernikovsky, Lithos 100, 66 (2008)

2. I.N. Gladkov, V.E. Distanov, A.A. Kirdyashkin, A.G. Kirdyashkin, Fluid Dynamics 47, 433 (2012)

3. M.I. Kuzmin, V.V. Yarmolyuk, V.A. Kravchinsky, Earth Sci. Rev. 102, 29 (2010)

4. A.A. Kirdyashkin, A.G. Kirdyashkin, N.V. Surkov, Rus. Geology Geophys. 47, 73 (2006) 